\title{
Dr. Victoria Neale Retires As Deputy Editor of JABFM
}

\author{
Marjorie A. Bowman, MD, MPA
}

( J Am Board Fam Med 2020;33:643-644.)

On July 31, 2020, Dr. Anne "Victoria" Neale retired as Deputy Editor of the Fournal of the American Board of Family Medicine ( $7 A B F M)$. I have had the extraordinary pleasure and honor of working with her the past 17 years. She is a terrific partner and I feel a profound sense of gratitude and loss.

Following Dr. John Geyman's tenure of 13 years, I was named the Editor of the fournal of the American Board of Family Practice ( $7 A B F P$ ) in January of 2003 (which became $7 A B F M$ in 2006 with the Board's name change). I had learned of Dr. Neale's interest in journal editing, and she agreed to jointly undertake the new version of 7ABFM.

Dr. Neale's educational background-MPH and $\mathrm{PhD}$ in Social Psychology-has been a great asset for the fournal. In addition to her editorial role, she has been a Professor in the Department of Family Medicine and Public Health Sciences; and Director, Division of Population Health, Wayne State University. She has a wide knowledge and acceptance in the field of family medicine, its partners, and practice-based research. She also led a program developing resources specific to the context of practice-based research. She was the Principal Investigator on an Agency for Health Care Research and Quality funded P30 Center Grant, the "PRIME Net Center in Practice-based Research and Learning," with an objective to build the pipeline of investigators prepared to conduct primary care research in the ambulatory clinic setting. Her authorship of more than 200 publications, and broad network of fellow researchers and faculty throughout the United States, have also advantaged $\mathcal{F} A B F M$.

Some historic context provides a deeper understanding of the risk that Dr. Neale agreed to undertake as Deputy Editor of $7 A B F M$. The publication of the Archives of Family Medicine had just

Conflict of interest: The author is the editor of the $7 A B F M$. been discontinued by its owner, the JAMA Network. As a result, the family of family medicine organizations was discussing joint sponsorship of a new journal to replace the Archives. If the American Board of Family Practice agreed to the joint sponsorship, it would mean providing financial support of 2 journals, that is, both the longstanding $7 A B F P$ and the new Annals of Family Medicine. The concerns over funding and the concurrent increasingly available computer resources led to intense conversations about the viability of potential online publication. "Going electronic" would save the large cost of mailing hard-copy journal issues to all family physicians. The final decision was to have both the Annals of Family Medicine and $7 A B F M$ be fully electronic, a major leap of faith at a time when few journals were published electronically, let alone as primarily online (a few physical copies continued to be published). This leap proved prescient as both journals continue to flourish.

The past 17 years have been extraordinary. Victoria has managed the editorial office with remarkable organization and efficiency such that there have been very few hiccups in the bimonthly publication of the fournal. In addition to running the editorial office, Victoria has served as the editor for a substantial percentage of the submitted manuscripts. Over the years, I have come to recognize that she is full of wise ideas and great suggestions, while also exhibiting an amazing attention to detail. I can think of many more attributes: she is an author and reviewer finder, efficient, timely, and responsible as only seen in the best of the best. And, she has been the joint author on countless Editors' Notes that are widely read.

Thankfully, success followed in no small part because of her outstanding efforts. Before and including 2003, $7 A B F P$ received about 150 submissions a year. In that first 2003 year we published 6 issues with a total of 68 articles and 302 
pages. The journal received 1.2 million hits. We were all excited and continue to be so. Submissions and readership have risen ever since. In 2019 we published 6 issues with 150 articles, 6.1 million hits and 511 citations, and the journal is read worldwide. In no small part, because of Dr. Neale's contributions.

Please join me in thanking Dr. Victoria Neale for 17 years of truly wonderful service to $7 A B F M$ and the field of family medicine! 